\title{
SEROPREVALENCE OF TOXOPLASMA GONDII INFECTION AMONG PREGNANT WOMEN ATTENDING ANTENATAL CLINIC IN MAJOR HEALTH CENTERS IN JOS NORTH, NIGERIA
}

\author{
${ }^{* 1}$ Akubuilo, A. S., ${ }^{2}$ Amali, O. and ${ }^{3}$ Onekutu, A.
}

\author{
${ }^{* 1,2,3}$ Department of Zoology, University of Agriculture Makurdi, Benue State, Nigeria \\ *Phone:09038080328*Email: josephadaora@gmail.com
}

\begin{abstract}
Toxoplasmosis is an infection caused by Toxoplasma gondii. It is reported that one third of the world's population is infected with the parasite. T. gondii represents the risk of miscarriages and congenital abnormalities in pregnancy. This study was carried out to ascertain the sero-prevalence of Toxoplasma gondii among pregnant women attending antenatal clinics in three major Health Centres in Jos North Local Government Area, Plateau State, Nigeria. Three hundred and eight four (384) pregnant women attending antenatal clinics were recruited for the study. Participants were screened for $T$. gondii specific antibodies using the Chromatographic Immuno-Assay (CIA) test method. Information on risk factors were obtained by the administration of a structured questionnaire. An overall seroprevalence of $11.7 \%$ was established. IgG antibodies represented $11.7 \%$ seroprevalence and $0.0 \%$ seroprevalence recorded for IgM antibodies. The highest seroprevalence of Toxoplasma gondii infection was established in women in their second trimester. Seropositivity was found to be significantly associated $(\mathrm{p}<0.05,95 \% \mathrm{CI})$ with type of drinking water, consumption of raw or fresh vegetables, previous history of miscarriage and older child with congenital deformation.
\end{abstract}

Keywords: antenatal clinics, Jos pregnant women, T. gondii, Toxoplasmosis, seroprevalence

LICENSE: This work by Open Journals Nigeria is licensed and published under the Creative Commons Attribution License 4.0 International License, which permits unrestricted use, distribution, and reproduction in any medium, provided this article is duly cited.

COPYRIGHT: The Author(s) completely retain the copyright of this published article.

OPEN ACCESS: The Author(s) approves that this article remains permanently online in the open access (OA) mode.

QA: This Article is published in line with "COPE (Committee on Publication Ethics) and PIE (Publication Integrity \& Ethics)". 


\section{INTRODUCTION}

Toxoplasmosis is a cosmopolitan parasitic zoonosis infecting human and other warm-blooded animals, including mammals and birds (Montoya et al., 2004; Tenter et al., 2002; Hills et al., 2002; Dubbey et al., 2009). The disease is distributed worldwide infecting almost one-third of the global population (Tenter, 2000). About 20-75\% of the world population has been found to be seropositive without any symptomatic episodes (Corrnea et al., 2007). Toxoplasma gondii, a single celled protozoan regarded as the most successful protozoan parasite on earth (Saeij et al., 2005; Riebeiro et al., 2008 and Mawhoob et al., 2010), is the causative agent of Toxoplasmosis with Felids as its definitive host.

The parasite is transmitted to humans via ingestion of raw or undercooked meat (Olusi et al, 1994), water contaminated with sporulated cysts (Amuta et al., 2012), oocyst contaminated environment (Nissapatron et al., 2011), and vertical transmission through the placenta from pregnant mothers to the foetus (Amuta et al., 2012). Acute primary maternal Toxoplasmosis acquired during pregnancy can cause significant morbidity and mortality in developing foetuses (Singh, 2003) and can induce abortions and loss of vision (Montoya and Liesenfeld, 2014) and for this particular reason the World Health Organization (WHO) has recommended, repeatedly, the regular monitoring of Toxoplasmosis in Humans and Animals.

In African region, Toxoplasma gondii overall prevalence rate has been reported to be as high as $92.5 \%$ (Ayi et al., 2009) and Congenital Toxoplasmosis is reported to be 2.5\% per 1000 live births and a Daily Adjusted Life Years (DALY) of 15\% per 1000 live births. In Nigeria, the prevalence rate of Toxoplasmosis by serological investigation has been estimated to vary from $7 \%-51.3 \%$ in immunocompetent pregnant women to $17.5 \%-52.3 \%$ in women with abnormal pregnancy and abortions (Deji-Agboola et al., 2010) and a reported prevalence rate of $29.1 \%$ and $0.8 \%$ for chronic and acute infections respectively (Ishaku et al.,2009).

Primary infections during pregnancy may result in severe damage or death of foetus and long term sequalae in the child. Congenital Toxoplasmosis is said to occur between 1 and 10 per 10,000 life birth in Europe (Montoya and Lisenfeld, 2004). The risk of congenital infection has been shown to increase with increase in trimesters, from 10 - 25\% in the first trimester to 60 - 90\% in the third trimester (Jones et al., 2001b; Dubbey and Jones 2008). Infections within the first trimester may result in death of foetus or spontaneous abortion and in the last trimester babies may be born asymptotic but develop symptoms later in life. These symptoms include hydrocephalus, retirochroiditis and intercranial calcification which occur in approximately $10 \%$ of all infected new-borns. There may also be mild infections such as reduced vision or even severe abnormalities like blindness, mental retardation and epilepsy (Tenter, et al., 2000)

Previous studies in major Nigerian cities including, Maiduguri, Abuja and Lagos revealed a prevalence of 22.2\% (Oyinloye, 2014), 44.4\% (Yusuf et al., 2016) for Toxoplasma gondii IgM antibodies and $7.6 \%$ and $32.6 \%$ for Toxoplasma IgM and Toxoplasma IgG respectively (Deji-Agboola, 2010) in pregnant women. Despite this, routine antenatal screening of Toxoplasma gondii infections and education on associated risk factors, the mainstream for monitoring and reducing the risk of infections with Toxoplasma gondii and congenital toxoplasmosis, is still not performed in health facilities in Plateau State. It is on this premise that this study was carried out to ascertain the 
prevalence of Toxoplasma gondii among pregnant women attending antenatal clinics in major Health Centres in Jos, Plateau State, Nigeria.

\section{MATERIALS AND METHODS STUDY AREA}

The study was carried out in Jos North, Plateau State, Nigeria. Jos North Local Government Area of Plateau State lies on longitude $9^{0} 55^{\prime} \mathrm{N} 8^{0} 54^{\prime} \mathrm{E}$ and latitude $9.917^{\circ} \mathrm{N} 8.900^{\circ} \mathrm{E}$. It houses the capital city of Jos as its headquarters. Jos North Local Government covers a total area of $291 \mathrm{~km}^{2}$ and has a population of 429,300 (2006 Census).

\section{ETHICAL CONSIDERATION}

Ethical approval was obtained from the health and ethical committees of the Plateau State Ministry of Health through Plateau State Specialist Hospital and from the ethical committees of Bingham University Teaching Hospital and Faith Alive Foundation.

\section{STUDY DESIGN}

The study was a cross-sectional study carried out among pregnant women attending antenatal care and included 384 women from three (3) selected health centres including, Bingham University Teaching Hospital, Faith Alive Foundation and Plateau State Specialist Hospital. The participants were taken through the informed consent process where the study objectives, risks, benefits and study procedures were explained in details in English Language and also interpreted in Hausa Language, where necessary. Only women who consented were enrolled in the study. After obtaining duly signed informed consent, the pregnant women who volunteered for the study were interviewed by the administration of a standard study questionnaire to obtain their socio-demographic, economic status information, medical histories as well as epidemiological risk factors. No names were used on any data collection forms, instead each pregnant woman examined was assigned a unique identity number.

\section{SAMPLE COLLECTION AND TESTING}

$2 \mathrm{ml}$ of venous blood was collected from each of the volunteers and emptied into well labelled EDTA test tubes. The collected blood samples were centrifuged at 3000 rpm for 5 minutes and the plasma was collected into well labelled plain tubes (Murebwayire, 2014). Plasma was screened for the presence of Toxoplasma gondii IgM and Toxoplasma gondii $\operatorname{IgG}$ antibody using Aria IgM and IgG test kits (CTK Biotech, California, USA) according to manufactures instructions.

\section{DATA ANALYSIS}

The data collected from the questionnaire and the laboratory test were entered into the Statistical Package for Social Sciences Programme (SPSS, Version 20). The data was subjected to chi square test of association. 


\section{RESULTS}

The result of the study shows an overall prevalence of $11.7 \%$ with prevalence of $8.3 \%, 10.0 \%$ and $15.97 \%$ for Bingham University Teaching Hospital, Faith Alive Foundation and Plateau State Specialist Hospital, respectively. The result also showed that chronic infection, as determined by the presence of IgG markers accounted for $100 \%$ of the positive cases in the current study while acute infection, identified by presence of IgM was not established in the current study.

Table 1: T. gondii sero-prevalence based on facility

\begin{tabular}{lccc}
\hline Facility & $\begin{array}{c}\text { Total Examined } \\
(\mathbf{n})\end{array}$ & $\begin{array}{c}\text { No. Positive } \\
\end{array}$ & $\begin{array}{c}\text { Prevalence } \\
(\boldsymbol{\%})\end{array}$ \\
\hline BHUTH & 120 & 10 & 8.33 \\
FAF & 120 & 12 & 10 \\
PSSH & 144 & 23 & 15.97 \\
Total & $\mathbf{3 8 4}$ & $\mathbf{4 5}$ & $\mathbf{1 1 . 7}$ \\
\hline
\end{tabular}

BHUTH: Bingham University Teaching Hospital

FAF: $\quad$ Faith Alive Foundation

PSSH: Plateau State Specialist Hospital

Table 2: The Distribution of the immune response to $T$. gondii among participants.

\begin{tabular}{lccc}
\hline Infection & Total Examined & $\begin{array}{c}\text { No. Positive } \\
\text { (n) }\end{array}$ & $\begin{array}{c}\text { Prevalence } \\
\text { \% }\end{array}$ \\
\hline Chronic infection & 384 & 45 & 11.7 \\
Acute Infection & 384 & 0 & 0 \\
Total & $\mathbf{3 8 4}$ & $\mathbf{4 5}$ & $\mathbf{1 1 . 7}$ \\
\hline
\end{tabular}

Table 3: Distribution of $T$. gondii in relations to demographic factors

\begin{tabular}{|c|c|c|c|c|c|c|}
\hline $\begin{array}{l}\text { Demographic } \\
\text { Characteristics }\end{array}$ & $\begin{array}{c}\text { No. } \\
\text { Examined } \\
\mathrm{N}=384\end{array}$ & No Positive & $\begin{array}{c}\text { Prevalence } \\
\%\end{array}$ & $X^{2}$ & $d f$ & P-value \\
\hline \multicolumn{7}{|l|}{ Age } \\
\hline $16-25$ & 115 & 13 & 11.3 & 0.13 & 3 & 0.716 \\
\hline $25-35$ & 204 & 25 & 12.3 & & & \\
\hline $36-45$ & 65 & 7 & 10.8 & & & \\
\hline Above45 & 0 & 0 & 0 & & & \\
\hline \multicolumn{7}{|l|}{ Occupation } \\
\hline Student & 39 & 3 & 7.7 & 0.591 & 2 & 0.44 \\
\hline Unemployed & 189 & 23 & 12.2 & & & \\
\hline Employed & 156 & 19 & 12.2 & & & \\
\hline \multicolumn{7}{|c|}{ Level of Education } \\
\hline Primary & 45 & 7 & 15.5 & 0.379 & 2 & 0.538 \\
\hline Secondary & 179 & 23 & 12.8 & & & \\
\hline Tertiary & 160 & 15 & 9.3 & & & \\
\hline \multicolumn{7}{|l|}{ Age of Pregnancy } \\
\hline $1^{\text {st }}$ Trimester & 62 & 5 & 8.1 & 0.811 & 2 & 0.368 \\
\hline $2^{\text {nd }}$ Trimester & 159 & 24 & 15.1 & & & \\
\hline $3^{\text {rd }}$ Trimester & 163 & 16 & 9.8 & & & \\
\hline
\end{tabular}

$X^{2}=$ chi square $\quad d f=$ degree of freedom 
Table 4: Distribution of $T$. gondii seroprevalence in relation to marital status and inhabitation

\begin{tabular}{lccccc}
\hline Characteristics & No. Examined & No. Positive & $\begin{array}{c}\text { Prevalence } \\
(\%)\end{array}$ & OR [95\% CI] & P-value \\
\hline $\begin{array}{l}\text { Marital status } \\
\text { Single }\end{array}$ & 5 & 1 & 20 & $1.90[0.21-17.42]$ & 0.466 \\
Married & 379 & 44 & 11.7 & & \\
& & & & & 0.249 \\
& & & & \\
Residence & & & & \\
Urban & 251 & 33 & 13.1 & & $0.83[0.76-3.07]$ \\
Rural & 133 & 12 & 9.0 & & $1.06[0.567-1.998]$ \\
Communities & 157 & 19 & 12.1 & \\
Hausa/Fulani & 227 & 26 & 9.4 & & \\
Non-Hausa & & & & \\
\hline
\end{tabular}

Table 5: Association of Toxoplasma. gondii seroprevalence with food and Water consumption

\begin{tabular}{|c|c|c|c|c|}
\hline Characteristics & $\begin{array}{c}\text { No } \\
\text { positive }\end{array}$ & Prevalence (\%) & OR $[95 \% \mathrm{CI}]$ & P-value \\
\hline \multicolumn{5}{|l|}{ Eat Vegetables } \\
\hline Yes & 42 & 11.2 & $0.51[0.11-2.46]$ & 0.39 \\
\hline No & 2 & 20 & & \\
\hline \multicolumn{5}{|l|}{ Preferred state } \\
\hline Fresh/Raw & 22 & 16.8 & $2.64[1.34-5.17]$ & 0.007 \\
\hline Steamed & 17 & 7.1 & & \\
\hline \multicolumn{5}{|l|}{ Water type } \\
\hline Treated & 19 & 8.1 & $1.4[0.22-0.77]$ & 0.04 \\
\hline Untreated & 26 & 17.6 & & \\
\hline \multicolumn{5}{|c|}{ Eating Undercooked Meat } \\
\hline Yes & 23 & 4.2 & $0.88[0.33-2.37]$ & 1.00 \\
\hline No & 22 & 11.9 & & \\
\hline
\end{tabular}

Table 6: Association of seroprevalence $T$. gondii with type of untreated water consumed by respondents

\begin{tabular}{|c|c|c|c|c|c|c|}
\hline $\begin{array}{l}\text { Untreated } \\
\text { Source }\end{array}$ & Water & Examined & No. Positive & $\begin{array}{c}\text { Prevalence } \\
(\%)\end{array}$ & OR $[95 \% \mathrm{CI}]$ & P-value \\
\hline \multicolumn{7}{|l|}{ Rain water } \\
\hline Yes & & 61 & 12 & 19.7 & $1.59[0.68-3.70]$ & 0.29 \\
\hline No & & 105 & 14 & 13.3 & & \\
\hline \multicolumn{7}{|l|}{ Well } \\
\hline Yes & & 41 & 15 & 36.6 & $5.04[2.07-12.27]$ & 0.0004 \\
\hline No & & 107 & 11 & 10.2 & & \\
\hline \multicolumn{7}{|l|}{ Boreholes } \\
\hline Yes & & 68 & 9 & 13.2 & $0.57[0.23-1.37]$ & 0.28 \\
\hline No & & 80 & 17 & 21.3 & & \\
\hline
\end{tabular}


Table 7: Distribution of T. gondii seroprevalence in relation to Presence of Pets in respondent's homes

\begin{tabular}{lcclll}
\hline Pets & $\begin{array}{c}\text { No } \\
\text { Examined }\end{array}$ & No Positive & $\begin{array}{c}\text { Prevalence } \\
(\boldsymbol{\%})\end{array}$ & OR[95\% CI] & P-value \\
\hline $\begin{array}{l}\text { None } \\
\text { Yes }\end{array}$ & 172 & 16 & 9.3 & $0.647[0.33-1.24]$ & 0.204 \\
$\begin{array}{l}\text { No } \\
\text { Cats }\end{array}$ & 212 & 29 & 13.7 & & \\
$\quad$ Yes & 25 & 4 & 16 & $1.477[0.483-4.517]$ & 0.516 \\
$\quad$ No & 359 & 41 & 11.1. & & \\
Dogs & 58 & 7 & 12.3 & $1.040[0.44-2.46]$ & 1.00 \\
Yes & 326 & 38 & 11.7 & & \\
$\quad$ No & & & & & \\
Other Animals & 258 & 27 & 10.4 & $0.701[0.370-1.328]$ & 0.311 \\
Yes & 126 & 18 & 14.3 & & \\
No & & & & & \\
\hline
\end{tabular}

Table 8: Association of T. gondii with Types of BOH

\begin{tabular}{lccccl}
\hline BOH Type & $\begin{array}{l}\text { No. } \\
\text { Examined }\end{array}$ & $\begin{array}{c}\text { No. } \\
\text { Positive }\end{array}$ & $\begin{array}{c}\text { Prevalence } \\
\text { \% }\end{array}$ & OR [95\%] & Pvalue \\
\hline $\begin{array}{l}\text { Miscarriages } \\
\text { Yes }\end{array}$ & 91 & 18 & 19.8 & $\mathbf{4 . 9 2}[\mathbf{1 . 2 5}-\mathbf{4 . 6 5}]$ & $\mathbf{0 . 0 0 8}$ \\
$\begin{array}{l}\text { No } \\
\text { Stillbirth }\end{array}$ & 293 & 27 & 9.2 & & \\
Yes & 21 & 1 & 4.8 & $0.363[0.05-2.77]$ & 0.49 \\
No & 363 & 44 & 12.1 & & \\
Birth defect & 7 & 4 & 57.1 & $\mathbf{1 0 . 9 3}[\mathbf{2 . 3 6 - 5 0 . 5 5}]$ & $\mathbf{0 . 0 0 4}$ \\
Yes & 337 & 41 & 10.9 & & \\
No & & & & \\
\hline
\end{tabular}

BOH: Bad Obstetric History

\section{DISCUSSION}

This study was carried out among pregnant women in three (3) major hospitals in Jos North Local Government Area of Plateau State, Nigeria with the use of the Immuno-Chromatographic Assay method. The overall sero-prevalence among pregnant women in this study area based on this study was $11.7 \%$. This result is comparable with a seroprevalence of $12.1 \%$, a seroprevalence of $13.8 \%$ and a seroprevalence of $12.2 \%$ as reported in Plateau State (Mariam, 2016), and in Rwanda respectively (Malarvizhi et al., 2012 and Murebwayire, 2014). This result is lower than the one found by Ishaku et al., (2009), Alayande et al., (2013) and Deji-Agboola et al., (2011), all who reported a sero-prevalence of 29.9\% in Zaria, Kaduna State, 27.7\% in Sokoto State and 32.8\% in Lagos State respectively. This difference in results may probably be attributed to variation in geographical and climatic conditions. Zaria in Kaduna Sate, Sokoto State and Lagos State all has a higher temperature and humidity than Jos, Plateau State, Nigeria. Higher temperature and humidity have been reported to favour oocyst sporulation. Sero-prevalence has been found to vary within the same country or even within locations in a particular region of a country (Ayi et al., 2009). This study result is in agreement with this statement. Plateau Specialist Hospital produced a higher sero-prevalence rate (16\%) than other study locations considered in this study. 
None of the 384 pregnant women examined this study was found positive for Toxoplasma gondii IgM antibodies indicating that all cases dictated in this study were not recent infections. This is in agreement with what was observed in Sudan by Musa et al., (2014), and in Greater Accra region Ghana by Ayeh-kumi et al., (2010) and Kwofie et al., (2012), whom all reported a 0\% sero-prevalence rate for Toxoplasma gondii IgM specific antibody. This is however lower than the rate of 5.4\% observed in Gabon (Mickoto et al., 2010).

In respect to age, although there was no statistical significance with $T$. gondii prevalence, the result of this study suggests an increase in sero-prevalence with increase in age. Sero-prevalence rate increased from pregnant women in the age bracket 16-25years to those in the age bracket 26- 35 years for Toxoplasma gondii IgG antibody. This is consistent to that published by Markovich et al., (2014), who observed an increase in seroprevalence of $T$. gondii with age. There was however a decrease in seropositivity with age from between those in the bracket age of 26-35years and those in the age bracket of 36 and above as also observed in Nairobi, Sefah-Boakye, (2015). This result might be because most pregnant women examined in this study were within the 26-35 age brackets. Prevalence of $T$. gondii was found to decrease with educational achievements. Pregnant women with just primary school certificate had highest prevalence to Toxoplasma gondii than those with higher qualifications. This result is in agreement with the one found in Jigjiga, East Ethiopia (Neguessie et al., 2017). This decreasing result might be due to increasing level of hygiene that comes with increased educational qualification.

Certain studies have previously shown that sero-prevalence of $T$. gondii can be attributed to socioeconomic and occupational status. Employed women were reported more highly susceptible to $T$. gondii than unemployed ones. This might be due to their easy access to meat and outdoor eating lifestyle (Mwambe, et al., 2013). In this present study however, the seropositivity for anti $T$. gondii was found to be quite similar for both employed and unemployed pregnant women as was observed in Rwanda by Murebywaire, (2014). In this study, results show that single pregnant women had a higher seropositivity to anti $T$. gondii antibody than married ones probably because single women had more outdoor lifestyles that made them more exposed to T. gondii, yet marital status showed no association with prevalence of $T$. gondii.

A seropositivity of $12.1 \%$ was observed in women belonging to the Hausa/Fulani Community, this prevalence was not found to be significant against the $11.5 \%$ prevalence found in pregnant women belonging to the Non-Hausa/ Fulani Community. This agrees with the result that was observed in Lagos State, Nigeria by Uttah et al., (2013). Uttah et al., 2013 stated that ethnicity has no effect on transmission of Toxoplasmosis.

Several authors have accounted drinking of untreated water as a risk factor and a significant source for the transmission of T. gondii in Nigeria (Mariam, 2016), and other countries (Murebywaire, 2014). Significant association was observed between $T$. gondii prevalence and drinking water type in this study. Pregnant women who drank from well water in this region showed significant association with Toxoplasma gondii transmission. This might be due to the reason that most wells constructed in this region are constructed without rings or proper surface covering. This lack of rings or proper covering allows in flow of surface runoffs during rainfalls. Drinking of untreated water was found to be associated with $T$. gondii spread by our results. This result portrays that oocyst can survive for long period in water hence individuals who drink untreated water maybe frequently exposed to $T$. gondii (Ishaku, et al., 2009). 
The presence of cats in the home has been attributed with significance with sero-prevalence of $T$. gondii infections (Alvarado, et al., 2006, Ballah et al., 2017). We observed in this study no significant association between cat ownership and sero-prevalence of $T$. gondii antibodies. This study result is in agreement with that published by Bello et al., (2017) who reported that the mere presence of cats in the home is not enough to confirm zoonosis but rather the handling of cat litter is of more importance. Significant association was observed between previous occurrence of bad obstetric history and seropositivity to $T$. gondii antibodies in this study. This study result is in agreement with the study results obtained in Gombe State, Nigeria (Ballah et al., 2017) who observed an association with previous bad obstetric history. In consideration with types of bad obstetric histories and its association with prevalence rate of $T$. gondii, bad obstetric history such as history of previous miscarriages and congenital malformations were found significant.

\section{CONCLUSION}

This study was carried out among pregnant women in three (3) major hospitals in Jos North Local Government Area of Plateau State, Nigeria with the use of the Immuno-Chromatographic Assay method. An overall sero-prevalence of $11.7 \%$ was established. The highest sero-prevalence of Toxoplasma gondii infection was established in women in their second trimester. Seropositivity was found to be significantly associated with type of drinking water, consumption of raw or fresh vegetables, previous history of miscarriage and older child with congenital deformation. The study therefore recommends that more education and sensitization on the risk factors associated with Toxoplasma gondii be intensified in the study area.

\section{REFERENCES}

Alayande, M.O., Edungbola, L.D., Fabiyi, J.P., Awosan, K.J. (2013). Occurrence of Antibody of Toxoplasma gondii among Pregnant Women with Obstetric Histories and at Different Trimesters in Sokoto, Northwest, Nigeria. American Journal of Research Communication, 1:240-247.

Alvarado-Esquivel, C. A., Sifuentus-Alvarez, S. C., Nano-Duarti, S., Estrada-Martinez, J. H., Diaz- Garcia, O., Lisensfeld, S.A, Martinez-Garcia, A. S., Canales-Molina, A. (2006). Seroepidemiology of Toxoplasma gondii Infection in Pregnant Women in a Public Hospital in Northern Mexico. BMC Infectious Diseses., 6:113-117

Amuta, E.U, Amali, O., Jacob, S.E. and Houmsou, R.S(2012). Toxoplasmosis gondii IgG Antibodies in HIV/AIDS Patients Attending Hospital in Makurdi Metropolis, Benue State, Nigeria. International Journal of Medicine and Biomedical Research, 1(3): 186-192

Ayeh-Kumi, P.F., Opoku, A.G., KwakyeNuako, G., Dayie, N.T.K.D., Asmah, R.H., Obeng Nkrumah, N., Lartey, M., Sagoe, A., Attipoe, M.I., Osafo, A.A.and Kretchy, J.P (2014). Seroprevalence of Toxoplasmosis among Patients Visiting the Korle-Bu Teaching Hospital, Accra, Ghana. Review in Infection, 1(3):147-150.

Ayi, I., Edu, A. Apea-Kubi, K. (2009). Sero-epidemiology of Toxoplasmosis amongst Pregnant Women in the Greater Accra Region of Ghana. Ghana Medical Journal.43: 107-114

Ayinmode, A.B., Adediran, O.A., Schares, G. (2016a). seroprevalence of Toxoplasma gondii and Neosporacaninum in Urbaan and Rural Dogs from Southwestern Nigeria. African Journal of Infectious Diseases, 10:25-28 
Ballah, F.M., Maikai, B.U., Magagi, A.A., Shuaibu, A.B., El-Nafaty, A.U., Sambo, Y.T., Auwal, A.A., Faruk, H.U., Sulieman, F. (2017). Seroprevalence and Risk of Toxoplasma gondii infection among Pregnant Woman at Federal Teaching Hospital in Gombe, Nigeria. Asian Journal of Medicine and Health, 3(2):1-5

Bello, H.S., Yahaya, A. U., Abdusalami, M.S.and Victor, O. Amusan (2017). Seroprevalence and Risk Factors of Toxoplasmosis among pregnant Women attending antenatal Clinic in Kaduna and Environs. International Journal of Tropical Disease and Health, 23(3): 1-11

Correa, D., Canedo, S.,Ortiz, A. B., Cabeller, O. H. and Rico-Torres, C. P. (2007). Congenital and Acquired Toxoplasmosis: Diversity and Roles of Antibodies in Different Compartments of the Host. Journal Parasite Immunology. 29(12):651-660.

Daka, V. M. (2014). Seroprevalence and Risk Factors of Toxoplasmosis in Individuals Attending Chipokotamayambia Clinic in Ndola, Zambia. A Dissertation Submitted to the Department of Disease Control. University of Zambia.

Deji-Agboola A. M., Busori, O. S., Osinupebi, O.A. Amoo, O. J. (2011). Seroprevalence of Toxoplasma gondii Antibodies among Pregnant Women Antenatal Clinic of Federal Medical Center, Lagos. International Journal of Medical Research. 2(4): 1135-1139.

Ishaku, B., Ajogi, I., Umoh, J., Lawal, I. and Randawa, A. R. (2009). Seroprevalence of Toxoplasma gondii Antibodies among Pregnant Women Attending Antenatal Clinic of Zaria, Nigeria. Research Journal of Medicine and Biomedical Science, $\mathbf{4 ( 2 ) : ~ 4 8 3 - 4 8 8 . ~}$

Kwofie, K. D. (2017). Risk of Mother to Child Transmissionof Toxoplasma gondii infection among Pregnant Woman in the Greater Accra Region. M.Phil Dissertation submitted at the Department of Clinical Microbiology, Kwame Nkrumah University of Science and Technology.

Malarvizhi, A., Viswanathan, T., Lavanga, V., Arul Sheeba Malar, S. and Moorthy, K. (2012). Seroprevalence of Toxoplasma gondii in pregnant Women. Journal of Public Health and Epidemiology, 4(6): 170-177.

Mariam, F. O. (2016). Seroprevalence and Risk Factors Associated with Toxoplasmosis among Pregnant Women receiving Antenatal care in Plateau State. Dissertation submitted to the Postgraduate School, Ahmadu Bello University, Zaria, Department of Community Medicine. 69.

Markovich, M.P., Shohat, T., Riklis, I., Anvi, R. Yujelevski-Rozenblit, D., Bassal, R., Roman, E, (2014). Toxoplasma gondiiInfection in the Isreali Population. Epidemiology and Infections.142(1):149-155.

Mawhoob, N., Putaiah, E. T., gamai, A. A., Alisallamkamal, O. and Arif, A. (2016). Prevalence of Toxoplasmosis among Pregnant Women and risk factors in Al-kaeda Province, IBB, Yamen. Journal of Biological Innovations. 5(6):824-834.

Murebwayire, E. (2014). Seroprevalence and Risk FactorInfections among Pregnant Women Attending Antenatal Care in Kigali, Rwanda. Dissertation Submitted at the University of Nairobi. Pg 1-84

Musa, A. R. and Mohammed, M. E. (2014). Seroprevalence of Toxoplasma gondii Infection among pregnant Women Attending Antenatal Clinics in Khartoum and Omduman Maternity Hospital, Sudan Journal of Coastal Life Medicine, 2(6):496-499.

Mwambe, B., Mshana, T., Kidenya, B. Massinde, A. N., Mazigo, H. D., Michael, D., Gross, U. (2013). Seroprevalence and Risk Factors Associated with Toxoplasma gondii Infections among Pregnant Women Attending Antenatal care in Mwanza, Tanzani. Parasitology Vectors, 6:222 
Nissaptorn, V., Suwanranth, C., Ling, L. Y. and Chandeying, N. (2011). Toxoplasmosis- Serological Evidence and Associated Risk Factors among Pregnant Women in Southern Thailand. American Journal of Tropical Medicine and Hygiene. 25(2):243-247.

Olusi, T. A., Ajayi, J. A., Makinde, A.A. (1994). Antibodies to Toxoplasma gondii in a Rat-eating Population in Benue State, Nigeria. Annals of Tropical Medicine and Parasitology. 88:217-218

Otubanjo, O. (2013). Parasites of Man and Animals. Concept Publishers, Lagos, Nigeria. 166-171

Sefah-Boakye, J. (2015). Seroprevalence of Toxoplasma gondii Infection among Pregnant Women in the Ashanti Region of Ghana, Evidence from the Manhyia Hospital, Kumasi. A Dissertation Submitted at the Department of Clinical Microbiology, Kwame Nkrumah University, Ghana. 6-7.

Singh, S. (2003). Mother to Child Transmission and Diagnosis of Toxoplasma gondii Infection during Pregnancy, Indian Journal of Medical Microbiology, 21:69-76.

Tenter, A., Heckeroth, A. and Weiss. L. (2000). Toxoplasma gondii from animal to Humans. International Journal of Parasitology, 30:1217-1258.

Uttah, E., Ogban, E. and Okonfia, C. (2013). Toxoplasmosis: A Global Infection, so widespread, so neglected. International Journal of Scientific and Research Publications, 3(6):1-6

Walker, M. E., Hjort, E. E., Smith, S.S., Tripathi, A., Hornick, J. E. and Hinchcliffe, E. H. (2008). Toxoplasma gondii Activity Remodels and Microtubule Network in Host Cells. Microbes Infection. (210):1440-1449

Yusuf, A. M. Yahaya, S. and Azeez-Akande O. (2016). Seroprevalence and Risk Factors of Toxoplasma gondii Infection (Toxoplasmosis) among HIV Seropositive Pregnant Women in a Tertiary Health Care, Kano. Journal of Medicine and Biomedical Science.7: 001-005.

Yusuf, A. M. Yahaya, S. and Azeez-Akande O. (2016). Seroprevalence and Risk Factors of Toxoplasma gondii Infection (Toxoplasmosis) among HIV Seropositive Pregnant Women in a Tertiary Health Care, Kano. Journal of Medicine and Biomedical Science.7: 001-005. 